\title{
¿ES POSIBLE LA CONVERSIÓN DE PENA EN UN ACTO POSTERIOR A LA SENTENCIA?, NECESIDAD DE REPLANTEAR EL ACUERDO PLENARIO N 3-2012
}

\author{
MANUEL ARRIETARAMÍREZ
}

\begin{abstract}
Resumen
El trabajo busca una respuesta al problema que afecta a un gran sector de la delincuencia primaria, de poca monta o de bagatela, donde los procesados se ven privados de su libertad por incumplimiento de las reglas de conducta impuestas en una sentencia condenatoria suspendida en su ejecución o reserva del fallo condenatorio, básicamente por la falta de pago de la reparación civil, a pesar de haberse satisfecho dicho pago pero con fecha posterior. Por lo que se plantea que la conversión de pena resulta viable en ejecución de sentencia condenatoria, como también realizando un juicio de ponderación entre dos principios de relevancia constitucional del mismo valor y jerarquía, como es el principio de inmutabilidad de la cosa juzgada vs. principio de humanidad de las penas.
\end{abstract}

Palabras claves: Reparación civil, sentencia condenatoria suspendida.

\begin{abstract}
The work aims to answer the problem that affects a large sector of the primary crime, petty or bagatelle, where the defendants are deprived of their liberty for breach of the rules of conduct imposed in a suspended sentence in its execution or reserve Conviction., basically for nonpayment of the civil repair, in spite of being satisfied such payment but postdated. By the way, as it stated that the conversion results viable in execution of a guilty verdict, as also making a weighting trial between two relevant constitutional principles of the same value and hierarchy, as it is the principle of immutability of the judged thing vs. principle of humanity of penalties.
\end{abstract}

Keywords: Civil repair, suspended sentence.

* Juez superior de la Tercera Sala de Apelaciones con funciones de Liquidadora de la Corte Superior de Justicia de Piura-Perú, doctor en Derecho y Ciencias Políticas, magíster en Derecho con mención en Derecho Penal por la Universidad Nacional de Piura y especialista en Criminalidad Organizada y nuevas formas de delincuencia. 


\section{Sumario}

1.- Introducción. 2.- Aspectos generales sobre las medidas alternativas a la pena privativa de libertad. 3.- La conversión de pena. 3.1.- Antecedentes legislativos. 3.2.Concepto. 3.3.- La conversión de pena en el Código Penal. 3.3.1.- Requisitos. 3.3.2.Revocatoria de la pena convertida. 3.4.- La conversión de pena según el Acuerdo Plenario $\mathrm{N}^{\circ}$ 3-2012/CJ-116. 4.- La interpretación jurídica. 4.1.- Planteamiento del problema de interpretación. 4.2.- Métodos de interpretación. 4.2.1.- El método literal o declarativo. 4.2.2.- El método de la ratio legis. 4.2.3.- El método sistemático. 4.2.4.- El método histórico. 4.2.5.- El método sociológico. 5.- La ponderación y los conflictos constitucionales. 5.1.- Aspectos generales. 5.2. Juicio de ponderación. 6.- La conversión de pena en un momento posterior a la sentencia. 7.- La conversión como resultado de ponderar principios de relevancia constitucional: principio de la cosa juzgada vs. principio de humanidad de las penas. 8.- Conclusiones. 9.- Referencias bibliográficas.

\section{Introducción}

El presente trabajo bajo el epígrafe ¿Es posible la conversión de pena en un acto posterior a la sentencia? Necesidad de replantear el Acuerdo Plenario $N^{\circ}$ 3-2012, pretende encontrar una respuesta a un problema que agobia a un gran sector de la delincuencia primaria, de poca monta o de bagatela, que incrementa la población penitenciaria, al verse privada de su libertad por incumplimiento de las reglas de conducta, impuestas en una sentencia condenatoria suspendida en su ejecución o reserva del fallo condenatorio, básicamente por la falta de pago de la reparación civil, quien a pesar que la satisfizo en fecha posterior, permanece innecesariamente privado de su libertad a la espera de acogerse a un beneficio penitenciario, porque el referido Acuerdo Plenario ha establecido, que luego de la revocatoria del régimen de suspensión de la pena, el cumplimiento efectivo y continuo de la pena privativa de libertad no existe ninguna posibilidad normativa de ser modificado o reducida en un momento posterior a la sentencia por no ser compatible con las disposiciones legales vigentes.

Sin embargo, considero que dicha afirmación no tiene el carácter absoluto, puesto que en el campo del derecho no hay categorías inmodificables en la medida en que la jurisprudencia supone el derecho en esencia y a su vez, la ciencia del derecho en cambio, en movimiento y en concordancia con el iter fáctico y evolutivo de los derechos fundamentales, lo que implica, que no 
podamos establecer categorías inmodificables en el Derecho Penal, esto a partir de que precisamente los derechos fundamentales suponen derechos dúctiles, esto es, no absolutos, los cuales pueden variar bajo reglas de jerarquía axiológica móvil.

En esa perspectiva, aplicando métodos de interpretación distintos al método literal, sustento del aludido Acuerdo Plenario, es posible concluir que la conversión de pena, resulta viable en ejecución de sentencia condenatoria, como también realizando un juicio de ponderación entre dos principios de relevancia constitucional del mismo valor y jerarquía como es el principio de inmutabilidad de la cosa juzgada vs. principio de humanidad de las penas.

\section{Aspectos generales sobre las medidas alternativas a la pena privativa de libertad}

Es política criminal de los diferentes ordenamientos jurídicos como una respuesta al implícito fracaso de la pena privativa de libertad, la necesidad de reducir y humanizar los espacios de aplicación de las penas privativas de libertad por medidas alternativas, con el fin de evitar que la prisión perjudique física o psíquicamente al condenado, vale decir, que la ejecución de las penas privativas de libertad aleje, desde su duración temporal a riesgo latente de deterioro de la persona del interno o de su resocialización.

No obstante, pese al respaldo doctrinal y legal de las medidas alternativas, hay unanimidad al limitar su aplicación a las penas de corta y mediana duración, en tanto que a las penas de mayor duración existe la necesidad de su mantenimiento; en ese sentido GARCÍA GÁLVEZ ha dicho que: "la pena de privación de libertad sigue siendo la espina dorsal del sistema de sanciones en materia de delincuencia grave" 1 .

Es pues, el ostensible fracaso de la cárcel como escenario de mejoramiento psicosocial de los delincuentes una grave realidad que la experiencia latinoamericana demuestra con claridad y dramatismo, el rol negativo de la cárcel y de las penas privativas de libertad; de ahí que ZAFFARONI afirma que: “La filosofía del tratamiento pasó por varias etapas sin que ninguna de ellas permitiera cambiar las características estructuralmente deteriorantes de la prisión. Resocialización es una expresión que, fuera del marco sistémico carece de contenido semántico y su uso equívoco se confunde en una multiplicidad de ideologías "re" (re- adaptación, re- inserción, re- educación,

1 GARCíA VALDEZ, Carlos (1995). Alternativas legales a la Privación de Libertad Clásica. En Juan Bustos Ramírez. Prevención y Teoría de la Pena. Cono Sur Santiago de Chile. Editorial Jurídica, p.190. 
re- personalización, etc.), que en definitiva, pretenden que la prisión pueda mejorar algo.

Teniendo en cuenta que el encierro institucional conforme a todas las investigaciones contemporáneas es siempre deteriorante, especialmente si es prolongada, resulta claro que las ideologías "re" no son utópicas sino absurdas. El efecto deteriorante de la prisionalización en concreto tiende a la reproducción del delito por introyección de los roles vinculados a los estereotipos que rigen la selección criminalizante"2

Por esa razón, en la actualidad se ha producido un viraje de una preocupación exclusivamente basada en la mayor capacidad rehabilitadora (o no desocializadora) de las penas alternativas, a la necesidad de estudiar mecanismos que tengan también capacidad de disminuir los índices de población recluida, aun cuando no sean verdaderas alternativas a la prisión. Es así que como consecuencia de todo ese proceso, coexisten distintos instrumentos formales cuya función común es impedir la ejecución material de penas privativas de libertad de corta e incluso mediana duración.

Así tenemos las penas limitativas de derechos como la Prestación de servicios a la comunidad y la limitación de días libres que pueden aplicarse como sustitutivas o alternativas de la pena privativa de libertad, cuando la sanción sustituida a criterio del Juez no sea superior a cuatro años; ; la conversión de la pena privativa de libertad, conversión de prestación de servicios a la comunidad y limitativa de derechos, conversión de pena de multa $^{4}$, suspensión de la ejecución de la pena ${ }^{5}$, reserva del fallo ${ }^{6}$ y la exención de pena ${ }^{7}$.

En el fondo se trata de instrumentos de despenalización que flexibilizan el rigor de las decisiones punitivas del Estado cuando estas se expresan en la conminación o aplicación de penas cortas privativas de libertad ${ }^{8}$, en los cuales subyace un mismo objetivo, neutralizar el acceso a la prisión por breves periodos de tiempo, en atención a que la experiencia criminológica

2 ZAFFARONI, Eugenio Raúl. (1991). La Filosofia del Sistema Penitenciario en el Mundo Contemporáneo, en Cuadernos de la Cárcel. Edición especial de NO HAY DERECHO, Buenos Aires, p. 61.

Artículo 32 del Código Penal.

Artículos 52, 55 y 56 .

Artículo 57.

Artículo 62.

Artículo 68.

8 PRADO SAldarRiaga, Víctor Roberto (2010). Determinación Judicial de la Pena y Acuerdos Plenarios. Lima. Editorial Idemsa, p. 222. 
demuestra que ese tipo de encarcelamientos breves, resultan estigmatizantes y negativos para el condenado, que contrarían toda expectativa de prevención general o especial, como también el principio de humanidad de las penas 9 .

\section{La conversión de pena}

\subsection{Antecedentes legislativos}

Su antecedente inmediato, el Código Penal de 1924, expresamente no contuvo un instituto como la conversión de pena, empero, al interior de su articulado, hemos podido advertir algunas formas de conmutación de penas privativas de libertad por medidas de seguridad, que se presentó en los casos de delitos perpetrados por "salvajes" 10 , "indígenas semi civilizados o degradados por la servidumbre y el alcoholismo" 11 , así mismo, asumieron el reemplazo de penas de internamiento por penas de penitenciaria, cuando el delito hubiera sido cometido por mayores de 18 y menores de 21 años de edad ${ }^{12}$. Sin embargo, el supuesto que más se acercó a la conversión de penas fue el artículo 194, que permitió sustituir, en etapa de ejecución, hasta un 90 por ciento de la pena privativa de libertad impuesta en la sentencia por el pago de una multa.

Igualmente, su fuente legal también la encontramos en el Código Penal Tipo para Latinoamérica, el cual fue recepcionado por el Proyecto de agosto de 1985, en cuanto contempla la conversión de la multa en prisión en los artículos 80 y 81 al señalar que: "si el condenado no pagare la multa, esta se convertirá a razón de un día-multa, sin perjuicio de la facultad del Estado, para ejecutarle en los bienes de aquél. En el caso de la conversión, la prisión no excederá de un año".

Ahora bien, uno de los principales rasgos característicos del proceso de reforma penal que inspiró el Código Penal de 1991, fue la clara vocación despenalizadora del legislador nacional, que se ve reflejada en la Exposición de Motivos donde se sostiene que la Comisión Revisora a pesar de reconocer

9 Llamado también principio de la proscripción de la crueldad. Según los postulados de este principio se rechaza por cruel toda sanción penal que resulte brutal en sus consecuencias para el sujeto. Se debe buscar una pena humanitaria en el sentido que se ejecute sin crueldad ni sufrimientos innecesarios para el penado, tomando en cuenta los lineamientos del Derecho de los derechos humanos.

10 Artículo 44.

11 Artículo 45.

12 Artículo 148. 
la potencia criminógena de la prisión considera que la pena privativa de libertad mantiene todavía su actualidad como respuesta para los delitos que son incuestionablemente graves. De esta premisa se desprende la urgencia de buscar otras medidas sancionadoras para ser aplicadas a los delincuentes de poca peligrosidad, o que han cometido hechos delictuosos que no revisten mayor gravedad. Por otro lado los elevados gastos que demandan la construcción y equipamiento de un centro penitenciario, obligan a imaginar nuevas formas de sanciones para los infractores que no amenacen significativamente la paz social y la seguridad colectivas ${ }^{13}$.

\subsection{Concepto}

La conversión de pena según PRADO SALDARRIAGA, no es otra cosa que la conmutación de la pena privativa de libertad impuesta en la sentencia por una sanción de distinta naturaleza ${ }^{14}$ y de uso facultativa por el juez ${ }^{15}$, es decir, que su concesión, aun cuando concurran los presupuestos legales, depende de que el juzgador considere su consecuencia, no constituyen derechos del penado ${ }^{16}$. Sin embargo, considero que es una verdad a medias, puesto que con la incorporación al catálogo de penas privativas de libertad, de la pena de Vigilancia Electrónica Personal17, al margen que se encuentre en vacatio legis ${ }^{18}$, en ella se determina que el juez podrá de oficio o a petición de parte, convertir la pena privativa de libertad en pena de vigilancia electrónica personal.

\subsection{La conversión de pena en el Código Penal}

La conversión de la pena privativa de libertad en el marco del Código Penal, se ubica en el Capítulo III De las Conversiones, que comprende III Secciones, la primera referida a la conversión de la pena privativa de libertad, la segunda, conversión de la pena de prestación de servicios a la comunidad y limitación de días libres, y la tercera, conversión de la pena de multa.

13 Exposición de Motivos del Código Penal de 1991.

14 PRADOSALDARRIAGA, Víctor Roberto. Op. cit., p. 241.

15 Tribunal Constitucional (2004) Exp. № 1140-2004-HC/TC. Cono Norte de Lima. Sentencia: 16 de junio de 2004. Fundamento. 2 parte pertinente: (...) En consecuencia, resulta meridianamente, claro que la conversión de pena es una facultad, y no una obligación del juez penal, de manera tal que al condena al cumplimiento de la pena privativa de libertad efectiva, a pesar de que ésta sea menor de 4 años (...)".

16 PRADOSALDARRIAGA, Víctor Roberto, op. cit. p.241.

17 Ley N 29499 publicada el 18 de enero del 2010.

18 Locución latina que significa: Vacación de la ley; plazo, inmediatamente posterior a su publicación, durante el cual no es obligatoria. 
En relación a la conversión de la pena privativa de la libertad, el artículo 52 sostiene: "En los casos que no fuere procedente la condena condicional o la reserva del fallo condenatorio, el juez, podrá convertir la pena privativa de libertad no mayor de dos años en otra de multa, o la pena privativa de libertad no mayor de cuatro años en otra de prestación de servidos a la comunidad, o limitación de días libres, a razón de un día de privación de libertad por un día de multa, siete días de privación de libertad por una jornada de prestación de servicios a la comunidad o por una jornada de limitación de días libres.

\subsubsection{Requisitos}

Con cargo a demostrar más adelante, que la conversión de la pena privativa de libertad operaría en un momento posterior a la sentencia, seguiremos a PRADO SALDARRIAGA, quien ha señalado que son requisitos para convertir la pena privativa de libertad: a) Se toma en cuenta el tipo de pena concreta impuesta, es decir, que en ningún caso debe ser superior a cuatro años de pena privativa de libertad, pues para convertir la pena de multa solo requiere que esta no sea superior a dos años; y b) Que en el caso no haya sido posible para el órgano jurisdiccional aplicar la suspensión de la ejecución de la pena o reserva del fallo condenatorio; en ese entendido, lo primero que debe verificar el juez es la suspensión de la ejecución de la pena o la reserva del fallo condenatorio; si ninguna de las dos opciones calza en la posibilidad del caso concreto, puede optar por la conversión de penas, lo que convierte a esta medida en una medida de carácter subsidiaria frente a otras medidas alternativas ${ }^{19}$.

\subsubsection{Revocatoria de la pena convertida}

Al respecto, el Código Penal ha establecido dos causales: a) Incumplimiento injustificado de la pena convertida, para ello el operador de justicia debe hacer un requerimiento previo al condenado que incumple la pena convertida y si persiste en el incumplimiento, entonces se reoca la conversión y se retorna a la pena original $\left.{ }^{20} ; \mathrm{y} \mathbf{b}\right)$ Revocatoria directa, toma en cuenta para su operatividad la pena conminada del delito cometido durante el proceso en el cual se está ejecutando la pena convertida ${ }^{21}$, vale decir, si

19 PradoSaldarRIAGA, Víctor Roberto. Op. cit., p. 242.

20 Artículo 53.

21 Artículo54. 
durante el período de cumplimiento de pena, el condenado comete nuevo delito doloso, cuya pena conminada sea superior a tres años, debe producirse la revocación de la conversión.

De ello se desprende que el efecto de la revocatoria de conversión es la reconversión de penas, que algunos autores denominan "cláusula del retorno o regla del regreso" 22 , lo cual determina que el condenado retorna al cumplimiento efectivo de la sentencia condenatoria, sin perjuicio de la aplicación de los descuentos que correspondan por cumplimiento de la pena convertida hasta antes de la revocación del régimen.

\subsection{La conversión de pena según el Acuerdo Plenario N³-2012/CJ-116}

El aludido Acuerdo Plenario que específicamente trata sobre la Función y operatividad de la Libertad Anticipada, prevista en el artículo 491, apartado 3 del Código Procesal Penal del 2004, por un lado, delimita lo que debe entenderse por libertad anticipada, al señalar que es una norma procesal, que no modifica, crea ni incorpora al ordenamiento jurídico una institución de derecho penal material o de ejecución penal material, ni a su amparo pueden introducirse pretoriamente modalidades de modificación, extinción o exención de penas privativas de libertad efectiva, no previstas por la ley penal material o de ejecución penal material23.

Por otro lado, precisa que la conversión de penas, es una medida alternativa, cuya función en el derecho nacional y extranjero ha sido siempre evitar que el condenado ingrese a un centro penal a cumplir la pena privativa de libertad que le fue impuesta en la sentencia condenatoria, y que, luego, en la misma sentencia, en atención sobre todo a su breve duración, el juez determine pena no privativa de libertad, y que será, en definitiva, la pena a cumplir por el condenado. El incumplimiento de la pena convertida también puede dar lugar a una revocatoria, que determinaría la conversión de la pena privativa de libertad en la pena privativa de libertad originaria. En este último caso, nuestra legislación solo admite un descuento en virtud de la denominada "regla del retorno", que regulan los artículos 53 y 54 del Código Penal. Cabe mencionar que la conversión de penas tiene un requisito negativo y que es, justamente, que no es procedente aplicar en el caso concreto la suspensión de la ejecución de la pena privativa de libertad, consecuentemente, menos procedente resulta ser que se aplique una

Ibid., p. 245.

23 Fundamento 17. 
conversión, en caso de revocación del régimen de suspensión de la ejecución de la pena impuesta24 (resaltado nuestro).

Concluye que es doctrina legal los criterios expuestos en los fundamentos 11 al 17 y 19, los que deben ser invocados por los jueces de todas las instancias judiciales, que solo pueden apartarse de las conclusiones de un Acuerdo Plenario si incorporan nuevas y distintas apreciaciones jurídicas respecto de las rechazadas o desestimadas, expresa o tácitamente, por la Corte Suprema de Justicia de la República ${ }^{25}$.

\section{La interpretación jurídica}

\subsection{Planteamiento del problema de interpretación}

$\mathrm{Al}$ respecto, RUBIO CORREA señala: "que tenemos varios niveles de interpretación en la problemática jurídica de un caso determinado. El primero es saber cuáles son las normas existentes (y los conceptos aplicables) al caso bajo estudio. Para dilucidar este primer nivel nos sirve la teoría de las fuentes del Derecho. Una vez que hemos definido las normas aplicables, tenemos un segundo nivel de problemas que consiste en saber qué dicen estas normas jurídicas. A este efecto nos sirve la teoría de la argumentación jurídica. Superados los dos niveles anteriores, nos encontramos con un tercero que consiste en averiguar exactamente qué quiere decir la norma. Este nivel debe ser abordado mediante la teoría de interpretación"26.

En relación a ello, diremos que la teoría de la interpretación jurídica, es la parte de la teoría general del Derecho destinada a desentrañar el significado último del contenido de las normas jurídicas cuando su sentido normativo no queda claro a partir del análisis lógico jurídico interno de la norma ${ }^{27}$

De ahí que los estudiosos están de acuerdo que la interpretación es una interpretación de significado al texto de una norma, asignación de línea de contenido a línea de expresión, como dirían los lingüistas. Sin embargo, está en discusión el carácter problemático de la interpretación, para ello LEÓN PASTOR se plantea dos interrogantes: 1) ¿Siempre se interpreta un texto

24 Fundamento 20.1.

25 Fundamentos 22 a 24.

26 RUBIOCORREA, Marcial (2000). El Sistema Jurídico (Introducción al Derecho). Octava edición. LimaPerú. Editorial de la Pontificia Universidad Católica del Perú, p. 245.

27 En la teoría hay una larga discusión sobre si siempre existe problema de interpretación o si este solo aparece cuando la literalidad de la norma no es suficientemente clara, por lo que la discusión es importante desde el punto de vista epistemológico. 
cuando se le atribuye un significado específico? y 2) ¿o es que solo se interpreta ante un caso dudoso?28

Para resolver las cuestiones planteadas, añade el referido autor, que es necesario hacer una definición sobre el alcance de la expresión "interpretar". Para los que responden afirmativamente la primera cuestión, interpretar es lo mismo que comprender un texto. Para los que se adhieren a la segunda posición, interpretar implica siempre un carácter problemático, una duda no resuelta, es decir, existe la posibilidad de escoger entre varios significados razonablemente sustentables., Concluye que en su perspectiva la interpretación es un esfuerzo sistemático, metódico y racional por comprender el mejor sentido de una norma determinada a la luz de los valores, principios y reglas del ordenamiento legal en su conjunto ${ }^{29}$

Sin embargo, debemos admitir que si a un texto corresponde un significado pacífico, no discutido al interior de la comunidad jurídica, la actividad cesará ante la claridad evidente del texto. Esta regla nos introduce en otra discusión, ahora en relación al carácter metódico del llamado "método literal". Para los que sostienen que interpretar es siempre comprender un significado, el método literal es el primero que debe aplicarse, y su ayuda es fundamental para llegar a la deseada claridad lingüística del texto; empero, para quienes consideran que interpretar implica resolver la duda razonable del intérprete, dicho método no es más el natural proceso de decodificación lingüística.

Si aceptamos que la interpretación trasciende la mera comprensión literal de un texto, entonces podremos vislumbrar situaciones en las cuáles es necesario aplicar un esfuerzo metódico y sistemático por "hallar", o en su defecto "construir" un mejor sentido de la textualidad normativa que tengamos entre manos, porque puede presentarse problemas de generalidad y abstracción del lenguaje legal, la indeterminación conceptual de los llamados "estándares jurídicos" o "conceptos jurídicamente indeterminados", que permite al intérprete una amplia flexibilidad para incluir o no dentro de determinadas expresiones lingüísticas contenidos de diverso alcance, como también los casos de "antinomias jurídicas".

28 LEÓN PASTOR, Ricardo (2001). En Módulo 1 Introducción al Razonamiento Jurídico. Academia de la Magistratura. Programa de Formación de Aspirantes para el Primer Nivel. Lima-Perú.

29 LEONPASTOR, Ricardo. Op. cit. 


\subsection{Métodos de interpretación}

Conocidos algunos de los supuestos para realizar el trabajo interpretativo, es necesario plantearse la interrogante respecto a la validez de la aplicación de diversos métodos de interpretación para dilucidar el sentido de una norma. Para ello la teoría de la argumentación jurídica ha trabajado dos grandes métodos interpretativos, uno llamado subjetivo que intenta descubrir la voluntad del legislador histórico, tal propuesta tiene que ver con la idea del juez como "boca de ley", que se rinde ante la magnanimidad de la voluntad del legislador; y por otro, el modelo objetivo, que se preocupa por la búsqueda de la intención de la norma, considerada al interior del ordenamiento jurídico.

Entre los métodos que ayudaran a desentrañar el sentido de la norma, tenemos:

\subsubsection{El método literal o declarativo}

El método literal es la puerta de entrada a la interpretación dentro de cualquier sistema jurídico basado en la escritura, y se le define como aquella que no atribuye a las disposiciones normativas nada más que su "propio significado literal", algunos tratadistas sostienen que cuando el método literal produce un resultado interpretativo suficiente, debe excluir la aplicación de los demás métodos de interpretación; sin embargo,, considero que si bien debe ser el primero a utilizar, ello de ninguna manera descarta a los demás métodos de interpretación, por la multiplicidad de problemas interpretativos que se presentan.

\subsubsection{El método de la ratio legis}

Según este método lo que busca no es la intención del legislador al dar la norma, sino la razón de ser de la norma jurídica propiamente dicha.

\subsubsection{El método sistemático}

Se llama sistemático a toda interpretación que pretende obtener el significado de una disposición a partir de su ubicación en el sistema del derecho, algunas veces en el sistema jurídico en su conjunto, más fundamentalmente, en un subsistema del sistema jurídico, esto es, el conjunto de las disposiciones que regulan una determinada materia o una determinada institución. Puede ser: 


\section{a) Por comparación con otras normas}

El procedimiento de interpretación consiste en esclarecer el que quiere decir la norma atribuyéndole los principios o conceptos que quedan claros en otras normas y que no están claramente expresados en ella; en otras palabras, el método por comparación con otras normas tiene que encontrar una ratio legis equivalente en las dos normas que se compara, las que siempre deben ser de carácter general.

\section{b) Por ubicación de la norma}

Este método basa su interpretación teniendo en cuenta el conjunto, subconjunto, grupo normativo ${ }^{30}$, etc., en el cual se halla incorporada la norma, a fin de que su qué decir sea esclarecido por los elementos conceptuales propios de su estructura normativa. En la practica la interpretación sistemática se utiliza cada vez, para decidir el significado de una disposición, es decir, no se busca la propia disposición de forma aislada, sino en el contexto en que encuentra ubicada.

\subsubsection{El método histórico}

Por este método la interpretación se hace recurriendo a los contenidos que brindan los antecedentes jurídicos, directamente vinculados a la norma de que se trata, y se fundamenta en que el legislador siempre tiene una intención determinada al dar la norma jurídica.

\subsubsection{El método sociológico}

Para el método sociológico la interpretación de la norma debe realizarse tomando en cuenta las variables sociales del más diverso tipo, del grupo social en el que va producirse la aplicación de la norma.

30 Los grupos normativos pueden a su vez ser insertados en estructuras superiores que se van diferenciando unas de otras dentro del Derecho. Uno de estos niveles superiores de estructuración es el que corresponde a las tradicionalmente llamadas ramas del Derecho, entendidas como subsistemas estructurales jurídicos que tienen determinadas características propias y distintas de las otras ramas. 


\section{La ponderación y los conflictos constitucionales}

\section{$5.1 \quad$ Aspectos generales}

En la ponderación, en efecto, hay siempre razones en pugna, intereses o bienes en conflicto, en suma razones que no suministran justificaciones diferentes a la hora de adoptar una decisión. Ponderar es, pues, buscar la mejor decisión cuando en la argumentación concurren razones justificatorias conflictivas y del mismo valor; por esa razón se dice que la ponderación es la forma de resolver esta incompatibilidad entre normas prima facie, a través del cual se puede fundamentar una relación de prevalencia condicionada entre los principios en colisión a lo que ALEXY llama la ley de la colisión ${ }^{31}$, para así, establecer cuál de ellos debe determinar la solución del caso concreto.

En relación a la ponderación, BERNAL PULIDO, ha dicho: "que es la forma en que se aplican los principios jurídicos, es decir, las normas que tienen la estructura de mandatos de optimización. Agrega, que estas normas no determinan exactamente lo que debe hacerse, sino que ordenan "que algo sea realizado en la mayor medida de lo posible, dentro de las posibilidades jurídicas reales y existentes" Las posibilidades están determinadas por los principios y reglas opuestas y las posibilidades reales se derivan de los enunciados fácticos" 32 .

\section{$5.2 \quad$ Juicio de ponderación}

La ponderación intenta ser un método para la fundamentación de ese enunciado de preferencia referido al caso concreto, en auxilio para resolver conflictos entre principios del mismo valor o jerarquía, cuya regla constitucional puede fundarse así "cuanto mayor sea el grado de la no satisfacción o de afectación de un principio, tanto mayor tiene que ser la importancia de la satisfacción del otro" ${ }^{\prime \prime 3}$.

En otras palabras, no se trata de establecer jerarquía de derechos ni prevalencias a priori, sino de conjugar desde la situación jurídica creada, ambos derechos o libertades, pesando cada uno de ellos, en su eficacia

31 ALEXY, Robert. (1997). Teoría de los derechos fundamentales, Traducción de Ernesto Garzón Valdez, Centro de Estudios Políticos y Constitucionales., Madrid, p.80.

32 Bernal PULIDO, Carlos (2007), En Modulo 2-Derecho Constitucional y Procesal Constitucional, Academia de la Magistratura, Octavo Curso de Preparación para el Ascenso en la Carrera Judicial y Fiscal-Primer Nivel de la Magistratura, Material de estudio elaborado por David Lobaton Palacios, Lima -Mayo 2007.

33 ALEXY, Robert. Op cit., p.161. 
recíproca. Lo característico de la ponderación es que con ella no se logra un supuesto válido para todo supuesto, sino que se logra solo una preferencia, relativo al caso concreto, que no excluye una solución diferente en otro caso, se trata, por tanto, de una jerarquía moral que no condice con la declaración de invalidez de uno de los bienes o valores en conflicto, ni a la formulación de uno de ellos, como excepción permanente frente al otro, sino a la posición abstracta de ambos, por más que ante cada caso de conflicto sea preciso reconocer primacía a uno u otro.

\section{La conversión de pena en un momento posterior a la sentencia}

Un aspecto problemático relacionado con la oportunidad para realizar la conversión de la pena privativa de libertad, que según postura adoptada por los Jueces Penales Supremos a través del Acuerdo Plenario N³ 3-2012, resulta inviable en ejecución de sentencia, por no ser compatible con las disposiciones legales vigentes ${ }^{34}$, ha conllevado que los operadores de justicia por temor a ser objeto de sanciones administrativas, desestimen toda pretensión de conversión en un momento posterior a la sentencia, sin tener en cuenta que utilizando otros métodos de interpretación jurídica distintos al literal que la Teoría de la Argumentación Jurídica aconseja, podría conducido a otra respuesta.

Ahora bien, si asumimos el método literal, por el cual, las normas son interpretadas según su propia textualidad, la conversión solo será posible al momento de emitir sentencia condenatoria; en cambio sí adoptamos el método sistemático, que busca el sentido de las normas según su ubicación en el contexto normativo o comparándolos con otras de su misma categoría, no de forma aislada, sino en el contexto en el que está ubicada en el discurso legislativo, la conversión sí es posible en ejecución de sentencia. Veamos.

La conversión de la pena privativa de libertad en el marco del Código Penal se ubica en el Título III De las Penas, Capítulo III De las conversiones, que a su vez, engloba III Secciones, la primera referida a la conversión de la pena privativa de libertad, la segunda, conversión de la pena de prestación de servicios a la comunidad y limitación de días libres, y la tercera, conversión de la pena de multa, comprendidas entre los artículos 52 al 56.

34 Fundamento 20 "Luego de la revocatoria del régimen de suspensión de la pena, el cumplimiento efectivo y continuo de la pena privativa de libertad no tiene ninguna posibilidad normativa de ser modificada o reducida (...): la revocatoria es una sanción y no es integrable con la conversión en otra pena no privativa de libertad, como prestación de servicios a la comunidad o multa". 
En relación a la conversión de prestación de servicios comunitarios, el artículo 55 señala: "Si el condenado no cumple injustificadamente, con la prestación de servicios o con la jornada de prestación de días libres aplicadas como penas autónomas, impuestas en caso de delitos o falta, dichas sanciones se convertirán en pena privativa de libertad (...)"; en cuanto a la conversión de la pena de multa, el artículo 56 precisa: "Si el condenado solvente no paga la multa o frustra su cumplimiento, la pena podrá ser ejecutada en sus bienes o convertida (...). Si el condenado deviene insolvente (...) la pena se convierte en una limitativa de derechos o de prestación de servicios a la comunidad (...). El condenado puede pagar la multa en cualquier momento (...)"; y con respecto a la conversión de la pena de Vigilancia Electrónica Personal, incorporada al Código Penal por Ley $\mathrm{N}^{\circ} 2949935$, en el artículo 1 tercer párrafo, señala: “(...). Para el caso de condenados la vigilancia electrónica personal es un tipo de pena, aplicable por conversión, luego de impuesta una sentencia de pena privativa de la libertad, que será dispuesta por el juez, a fin de garantizar el cumplimiento de la pena y la resocialización del condenado", e indica en el artículo 2 inciso b) "Para el caso de condenados, el juez podrá revertir la conversión otorgada en una pena privativa de libertad" (lo resaltado es nuestro).

De lo expuesto, podemos colegir, que si se permite la conversión y reconversión de la pena de vigilancia electrónica personal, prestación de servicios y la pena de multa en un acto posterior a su imposición, nos preguntamos qué razón impediría al operador judicial para convertir o reconvertir la pena privativa de libertad en ejecución de sentencia, verbigracia el siguiente el itinerario: pena suspendida en su ejecución-pena privativa de libertad efectiva-pena suspendida o convertirla en vigilancia electrónica personal, en prestación de servicios comunitarios u otras según su equivalencia.

Evaluación que se ve reforzada con el artículo 478.3 del Código Procesal Penal del 2004 que al regular el Proceso de Colaboración Eficaz ha establecido: "Si la colaboración se inicia con posterioridad a la sentencia, el juez a solicitud del fiscal previa celebración de una audiencia privada (...)

35 Artículo 1 "La vigilancia electrónica personal es un mecanismo de control que tiene por finalidad monitorear el tránsito tanto de procesados como de condenados, dentro de un radio de acción y desplazamiento, teniendo como punto de referencia el domicilio o lugar que señalen estos (...). Para el caso de condenados, la vigilancia electrónica personal es un tipo de pena, aplicable por conversión, luego de impuesta una pena privativa de libertad que será dispuesta por el juez a fin de garantizar el fin de la pena y la resocialización del condenado". 
podrá conceder (...) conversión de pena privativa de libertad por multa, prestación de servicios o limitación de días libres, conforme a las equivalencias previstas en el artículo 52 del Código Penal" (lo resaltado es nuestro).

En el supuesto que la pena privativa de libertad se encuentre ejecutando, solo sería viable, en tanto y en cuanto, la pretensión del condenado no se encuentre bajo los alcances del Código de Ejecución Penal, pues si ello fuere así, tendría que recurrir al órgano judicial correspondiente para obtener su libertad, postulando el beneficio penitenciario de semi libertad ${ }^{36}$ o liberación condicional ${ }^{37}$, que según el caso, se obtendrá cuando el interno ha cumplido un tercio o la mitad de la pena impuesta, actuar in contrario es violentar el principio de legalidad.

\section{La conversión como resultado de ponderar principios de relevancia constitucional: principio de la cosa juzgada vs. principio de humanidad de las penas}

Como una postura subsidiaria, considero que la conversión de la pena privativa de libertad en ejecución de sentencia, también sería viable en virtud de un juicio de ponderación, que como hemos dicho líneas arriba, opera cuando existe conflicto entre dos principios de relevancia constitucional, del mismo valor y jerarquía, por un lado tenemos, la inmutabilidad de la cosa juzgada ${ }^{38}$, sustento del Acuerdo Plenario No 3-2012 para desestimar la libertad anticipada y conversión de pena, y por otro, el principio de humanidad de las penas ${ }^{39}$, que implica que el juzgador debe hacer uso de las penas privativas de libertad como última ratio, y en tanto esta constituya entre todas las sanciones punitivas previstas en la normatividad penal la sanción menos degradante y denigratoria de la dignidad humana. Ello es así, por las siguientes consideraciones:

36 Artículo 48 "La semi libertad permite al sentenciado egresar del establecimiento penitenciario, para efectos de trabajo o educación, cuando ha cumplido la tercera parte de la pena y no tiene proceso pendiente con mandato de detención (...)".

37 Artículo 53 “La liberación condicional se concede al sentenciado que ha cumplido la mitad de la pena siempre que no tenga proceso pendiente con mandato de detención (...)".

38 Artículo 139.de la Constitución. Son principios y derechos de la función jurisdiccional: 13) La prohibición de revivir procesos fenecidos con resolución ejecutoriada. (...)".

39 Este principio se encuentra reconocido formalmente en los literales g y h del artículo 2 incisos 21 y 22 del artículo 139 de la Constitución Política del Estado, garantiza que las sanciones penales no sobrepasen los niveles de incidencia sobre los ciudadanos que son admisibles en el marco de las condiciones del contrato social. Por este principio el Estado no puede diseñar, aplicar ni ejecutar sanciones penales que afecten la dignidad de la persona, ni que dañen la constitución psicofísica de los condenados. 
a) La inmutabilidad de una sentencia condenatoria que adquiere la calidad de cosa juzgada, está relacionada con los hechos y circunstancias que se dan por probadas, que han servido de soporte para fundar la condena del imputado e implica la prohibición de que por los mismos fundamentos se pueda volver a juzgar a la misma persona, situación que no se presente con la conversión de pena, pues el status jurídico de aquella se mantiene incólume y la seguridad jurídica igual, lo que varía es la forma de ejecutarse.

b) Así mismo, la persecución penal del Estado no pierde vigencia con la conversión de pena, tampoco los fines de la pena se ven diluidos, pues la rehabilitación y reincorporación del penado a la sociedad, no solo se logra con el encarcelamiento del agente, sino también en libertad como es la ratio legis de la conversión, por esa razón el legislador ha incorporado al Código Penal, medidas alternativas y sustitutivas a la pena privativa de la libertad como la conversión.

c) Ahora bien, en los delitos materia de conversión de pena, no se refleja dosis de criminalidad o peligro social gravitante para la Comunidad, que exija una mayor represión por parte del Derecho Penal. De allí que el Congreso consiente que las cárceles no es solución a todos los casos penales, instituyó la figura del principio de oportunidad y acuerdo reparatorio ${ }^{40}$, a través de los cuales se privilegia el resarcimiento de los daños y perjuicios a la víctima como una prioridad de modelo de justicia criminal o justicia restaurativa ${ }^{41}$ a cambio que el titular de la acción penal renuncie al jus puniendi o derecho de perseguir.

d) En relación al item precedente, diremos que si la conversión de pena deriva de un delito, cuyo origen no era perseguible penalmente bajo condición de resarcir el daño a la víctima, nos preguntamos ¿qué razón justificaría rechazar la conversión de la pena en acto posterior a la condena?, si el condenado satisfizo la

40 Artículo 2 del Código Procesal Penal.

41 Entendida esta como la respuesta evolutiva al delito que brinda a las víctimas la oportunidad de obtener reparación, sentirse más seguras e intentar cerrar una etapa, permite a los delincuentes comprender mejor las causas y los efectos de su comportamiento para asumir una genuina responsabilidad y posibilita a las comunidades comprender las causas profundas de la acción delictiva, promueve el bienestar comunitario y prevenir la delincuencia. personas, favorece el entendimiento y promueve la armonía social mediante la recuperación de las víctimas, los delincuentes y las comunidades. 
regla de conducta que su incumplimiento genero la revocatoria, vervigracia el pago de las pensiones alimenticias o la reparación civil; en esa perspectiva también nos preguntamos la conversión de pena genera inseguridad jurídica, la respuesta es obvia.

e) En concordancia con lo anterior, podemos advertir que en esa ponderación, el principio de inmutabilidad de la cosa juzgada debe ceder a favor del principio de humanidad de las penas, por encontrar mayor justificación; el delincuente goza de una nueva oportunidad para continuar el proceso de resocialización en libertad y el Estado se aliviaría de los costos que significa subvencionar la alimentación de un gran sector de la población penal.

\section{Conclusiones}

a) Se ha demostrado que la conversión de la pena privativa como una medida alternativa a la pena privativa de la libertad, es posible aplicar en ejecución de sentencia, en primer lugar, utilizando métodos de interpretación distintos al método literal, y en segundo lugar, realizando un análisis de ponderación de principios constitucionales, sin que ello ponga en cuestión la seguridad jurídica, concebida como un bien jurídico protegido que hace referencia a un conjunto de acciones o medidas que están destinadas a salvaguardar el desarrollo de la vida comunitaria dentro de un contexto de paz, tranquilidad y orden.

b) La aplicación de la conversión de pena en ejecución de sentencia, abre la posibilidad que gran cantidad de infractores de la ley penal que han incrementado la población penal, entre otros, los casos por el delito de Omisión a la Asistencia Familiar, puedan egresar y cumplir el resto de la pena en libertad, siempre que no hayan superado el tiempo requerido para acogerse a los beneficios penitenciarios.

c) Además de considerar que las penas cortas efectivas serían contraproducentes con los propósitos de la prisión, pues en corto tiempo no se puede hacer efectivo un programa de resocialización, y adicionalmente se dice que el efecto contaminante de la prisión convierte a la prisión corta en negativa y perniciosa, ya que genera perspectivas y distorsiones en la valoración y criterios del primario frente al crimen, lo que origina que se afirme que la cárcel no 
amedrenta a quien delinque, sino que más bien lo fortalece y profesionaliza.

\section{Bibliografia}

GARCíA VALDEZ, Carlos. Alternativas legales a la Privación de Libertad Clásica. En Juan Bustos Ramírez. Prevención y Teoría de la Pena. Como Sur Santiago de Chile. Editorial Jurídica, 1995.

ZAFfaroni, Eugenio Raúl. "La Filosofía del Sistema Penitenciario en el Mundo Contemporáneo", En Cuadernos de la Cárcel. Buenos Aires. Edición especial de NOHAY DERECHO, 1991.

Prado SaldarRiaga, Víctor Roberto. Determinación Judicial de la Pena y Acuerdos Plenarios, Lima. Editorial Idemsa, 2010.

RUBIO CORREA, Marcial. El Sistema Jurídico (Introducción al Derecho), Octava Edición. Lima-Perú. Editorial de la Pontificia Universidad Católica del Perú, 2000.

LEÓN PASTOR, Ricardo. Introducción al Razonamiento Jurídico. Academia de la Magistratura. Programa de Formación de Aspirantes para el Primer Nivel. Módulo 1, Lima-Perú, 2001.

ALEXY, Robert. Teoría de los derechos fundamentales, Traducción de Ernesto Garzón Valdez, Centro de Estudios Políticos y Constitucionales., Madrid, 1997.

BerNal PULIDO, Carlos. Derecho Constitucional y Procesal Constitucional, Academia de la Magistratura, Octavo Curso de Preparación para el Ascenso en la Carrera Judicial y Fiscal-Primer Nivel de la Magistratura, Modulo 2, Material de estudio elaborado por David Lobaton Palacios, Lima, 2007.

ATIENZA, Manuel. Proyecto de una Teoría de la Argumentación Jurídica-Las Razones del Derecho. Teorías de la Argumentación Jurídica, Madrid, 1997.

GARCíA E. Alonso. La interpretación de la Constitución, Centro de Estudios Constitucionales. Madrid, 1984.

Castillo Alva, José Luis. Principio de Derecho Penal. Lima. Gaceta Jurídica, 2004.

HURTADO POZO, José. "Suspensión de la ejecución de la pena y reserva del fallo". En El Sistema de Penas del Nuevo Código Penal. Anuario de Derecho Penal. Lima, 1999.

PRIETO SANCHIS, Luis. "Circunstancias y Supuestos de la Creación Judicial del Derecho". Madrid. Tecnos, 1987.

PRIETO SANCHIS, Luis. Justicia Constitucional y Derechos Fundamentales, Madrid. Trotta, 2003. 
MIR PUIG, Santiago. "Tendencias político- criminales y alternativas a la prisión en la Europa actual". En Revista del Ilustre Colegio de Abogados del Señorí de Vizcaya $\mathrm{N}^{\circ} 34,1987$.

GASCÓN ABELLÁN, Marina y GARCíA FiguerOA, Alfonso. La Argumentación en el Derecho. Algunas Cuestiones fundamentales. Lima. Palestra Editores, 2003.

BERNAL PULIDO, Carlos (2003). El principio de proporcionalidad y los derechos fundamentales. Lima, Perú. Editorial Universidad de Ciencias aplicadas Centro de Información (UPC).

PRADO SALDARRIAGA, Víctor Roberto, DEMETRIO CRESPO, Eduardo, Velásquez Velásquez, Fernando, VAN WeEzel, Alex, Couso, Jaime. "Determinación judicial de la pena". Instituto Pacífico S.A.C. Lima, Perú, 2015.

CASTILlO Alva, José Luis, CASTILlo CóRDOVA, Luis. El Precedente judicial y el Precedente constitucional. Lima Perú. ARA Editores E.I.R.L, 2008.

RAZ, Joseph. ¿Por qué Interpretar? ISONOMIA, Revista de Teoría y Filosofía del Derecho. Méjico. 1996. No5, p. 25-40, 1996.

Código PenAL. Jurista Editores E.I.R.L, Lima, Perú, 1991.

Código Procesal Penal. Jurista Editores E.I.R.L., Lima, Perú, 2004.

Códigode EJECUCIÓN PENAL. Jurista Editores EIRL, Lima, Perú, 1991.

CONSTITUCIÓN POLÍTICA DEL PeRÚ. Jurista Editores E.I.R.L, Lima, Perú, 1993. 